Prior to this combination a student commencing his studies at one of the recognised provincial hospitals was allowed to count a year's hospital practice as one of the four years of study required to obtain his diploma-i.e., a student having spent his first year at a recognised provincial hospital entered at a medical school, and at the end of his second winter session at such school could present himself for his Primary College, now called the Second Examination. A year subsequently he was allowed to present himself for the Final, in virtue of having spent a year at a recognised provincial hospital. By the present arrangement, he is not permitted to present himself for his Final unti two years after passing his Second Examination, and thus the student who did a year's practical work before entering a medical school is, as far as time goes, no better off than his fellow who came straight to such medical school without any previous training; in fact, the provincial hospital student has lost a year. It may be suggested that men can come into the country after their second year in London, but this would not take place for the following reason. By going into the country at that time, they would lose all position at their school as third-year's students, and consequently all chance of obtaining valuable appointments for which otherwise they would be eligible. Thus the large amount of valuable experience and practice obtainable at the provincial bospitals are lost to future students, whilst the loss of a working staff of students to such hospital itself is a very serious one. I would suggest that all candidates for election to the Medical Council be asked to give their support, in order to get the state of things complained of altered. I am, Sir, yours truly,

JAS. BANTAR'T,

Exeter, Nov. 9th, 1886 .

Senior Surgeon to the Devon and Exeter Hospital.

$*_{*}^{*}$ Under the present arrangement, instruction in Chemistry, Practical Chemistry, Materia Medica, and Pharmacy may be given before the student's entry at a recognised medical school, in the first year of medical study after registration, and the student can spend his time during this period at no better place than at a provincial hospital. He can pass his final examinations in three yeais and a half after entering a medical school, and few students have ever obtained the diplomas of M.R.C.S. and L.R.C.P. in less time than this under the old regulations.--ED. L.

\section{THE QUEEN'S JUBILEE : A SUGGESTION.} To the Editor of THe LANCET.

SiR,--I not infrequently hear it asked, "How is the medical profession going to commemorate the Queen's Jubilee?" Would you grant me space to make one suggestion? There is one medical corporation -the Royal College of Surgeons of England-that stands greatly in need of a "Hall," a building commensurate with the present position of the College, where Members and Fellows may hold their meetings; in which all collegiate entertainments might be given, rather than in the library and museum as at present; in which all the works of art might be placed. Nothing can be less fitting than the present position of the busts-a collection nulli secundus. The pictures as works of art, with a few exceptions, are not great; but they represent great men, and should be placed where all members of the corporation might have an opportunity of seeing them. The College is greatly indebted to the Queen for the gracious interest Her Majesty took in the new building on the Embankment, and it might be called the "Queen's Hall," and contain a statue of Her Majesty. It would also serve as an expression of the appreciation of the College of the great bequest we are about to receive. There would be little difficulty in finding within the precincts of the College the necessary space. I trust I may be pardoned for thus intruding myself on so important an occasion. It is singular that the position of the new Examination Hall in the Savoy is one of those suggested to Dr. William Hunter, when, in 1764 , previous to building his school in Great Windmill-street, he offered the Government to build a school and museum at his own cost if he were granted the ground. This offer was refused, and that magnificent collection he brought together is in Glasgow.

I am, Sir, your obedient servant,

Athenæum Club, Nov. 9th, 1886.

CHARLES HAWKINS.

\section{"DEATH OF A PASTEUR PATIENT UNDER SUSPICIOUS CIRCUMSTANCES."}

\section{To the Editor of THE LANCET.}

SIR,-A paragraph with the above sensational heading appeared in a number of newspapers in this district last Thursday, the anno uncement being slightly varied in some of them. The deceased, A. Wilde, was stated to have been bitten by an unfortunate man named Oates, who died of rabies at Rotherbam some weeks ago, and whom he was assisting to nurse. Wilde subsequently went to Paris and was treated by Pasteur. Considering the serious character of the case, involving a possible (and probable) charge of failure against Pasteur's method, if not the conclusion being drawn that the treatment itself was the cause of death, $\mathbf{I}$ went at once to Rotherham, my object being to obtain some material from the deceased for test-inoculations to prove whether any, and what kind, of rabic virus was present. There is no difficulty in distinguishing whether the virus in such a case has emanated from a dog (even after passing through a human subject) or from the rabbit (which is the virus used by Pasteur). On arriving at Rotherham, $\mathrm{I}$ was not a little surprised to find that nothing was known about the startling news, and that no "suspicious circumstances" had occurred: in fact, it was evident that the thing was a cruel and improper canard. Dr. Foote, the medical attendant, told me the cause of death was acute congestion of the lungs, and that there had never been a symptom simulating rabes. Dr. Waller, who made the postmortem examination, informed me that all the appearances were quite in consonance with the symptoms seen during life, and that there was absolutely nothing to support the sensational newspaper report. I accordingly felt it would be quite useless and unnecessary to make any inoculations, as the cause of death was clear. The reprehensible manufacture of such canards cannot be too strongly condemned.

I am, Sir, your obedient servant,

Bradford, Nov. 9th, 1886

THOs. WHITESID HIMr.

P.S.- I may add that Wilde was not really intentionally bitten by the deceased, Oates. But in a struggle while trying to get that unfortunate man into bed he suffered an abrasion of the skin, quite justifying the anxiety which caused him to be sent to Pasteur for treatment.

\section{INDUCTION OF LABOUR IN CASES OF ALBUMINURIA IN PREGNANCY.}

\section{To the Editor of THE LANCET.}

SrR,- The letters from Dr. Donald and Dr. Cullingworth (Nov. 6th) satisfactorily dispose of the doubts expressed by Dr. Murphy and myself relative to the potency of the drugs, pilocarpine and jaborandi, used in the case recorded Sept. 18th. They prove that these two drugs are not infallible diaphoretics. They also lend support to the view that when sweating is produced and good done, it is probably the sweating rather than any specific action of the drug which does the good, for in this case no good was done and no sweating was produced. If Dr. Donald will read my letter again, he will see that I did not say that if the drng produces marked diaphoresis then good will follow. I think it very likely that cases may occur in which the pilocarpine causes the usual copious perspirations, without having any beneficial effect in cases like that of Dr. Culling worth, or even in cases of puerperal convulsions. But believing that pilocarpine does good because of its diaphoretic properties, and not because of any of its other physiological effects, I am not surprised to find that in this case, in which, for some reason or other, no sweating was caused, no benefit resulted. Indeed, hot-air baths were tried without benefit, and it is not stated whether they produced sweating or not, but it is stated further on that the skin was very dry. With regard to the ecbolic action of pilocarpine, Massman of St. Petersburg appears to have accidentally found it out (vide THF LANCET, Feb. 8th, 1879) while using the drug in a case of pregnancy with dropsy. In my first case of puerperal eclampsia in which pilocarpine was used I did not pay attention to this point, but from subsequent experience I feel sure it was the pilocarpine which caused the death of the child by setting up tetanic uterine contraction. In my second case the contractions were quite remarkable after the use of pilocarpine. Dr. Donald says the weight of 